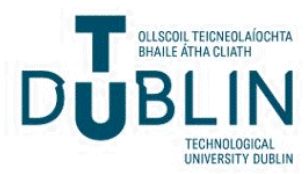

Technological University Dublin

ARROW@TU Dublin

\section{Development of a Selective Inhibitor for Kv1.1 Channels Prevalent in Demyelinated Nerves}

\author{
Ahmed Al-Sabi \\ American University of the Middle East, Kuwait \\ Declan Daly \\ Dublin City University, Glasnevin, Dublin 9, Ireland \\ Myles Rooney \\ Dublin City University, Glasnevin, Dublin 9, Ireland
}

See next page for additional authors

Follow this and additional works at: https://arrow.tudublin.ie/schfsehart

Part of the Food Biotechnology Commons, Food Chemistry Commons, and the Food Microbiology Commons

\section{Recommended Citation}

A. Al-Sabi, et al. (2020). Development of a selective inhibitor for Kv1.1 channels prevalent in demyelinated nerves, Bioorganic Chemistry, 100 (2020) 103918. DOI:10.1016/j.bioorg.2020.103918

This Article is brought to you for free and open access by the School of Food Science and Environmental Health at ARROW@TU Dublin. It has been accepted for inclusion in Articles by an authorized administrator of ARROW@TU Dublin. For more information, please contact arrow.admin@tudublin.ie, aisling.coyne@tudublin.ie, gerard.connolly@tudublin.ie.

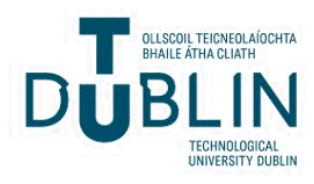




\section{Authors}

Ahmed Al-Sabi, Declan Daly, Myles Rooney, Cian Hughes, Gemma K. Kinsella, Seshu Kaza, Kieran Nolan, and J. Oliver Dolly 


\title{
Development of a selective inhibitor for Kv1.1 channels prevalent in demyelinated nerves
}

\author{
Ahmed Al-Sabi ${ }^{\mathrm{a}, \mathrm{b}}$, Declan Daly ${ }^{\mathrm{c}}$, Myles Rooney ${ }^{\mathrm{c}}$, Cian Hughes ${ }^{\mathrm{c}}$, Gemma K. Kinsella ${ }^{\mathrm{d}}$, \\ Seshu K. Kaza ${ }^{\mathrm{b}}$, Kieran Nolan ${ }^{\mathrm{c}, *}$, J. Oliver Dolly ${ }^{\mathrm{b}}$ \\ ${ }^{\text {a }}$ College of Engineering and Technology, American University of the Middle East, Kuwait \\ ${ }^{\mathrm{b}}$ International Centre for Neurotherapeutics, Dublin City University, Glasnevin, Dublin 9, Ireland \\ ${ }^{\mathrm{c}}$ School of Chemical Sciences, Dublin City University, Glasnevin, Dublin 9, Ireland \\ ${ }^{\mathrm{d}}$ School of Food Science and Environmental Health, College of Sciences and Health, Technological University Dublin, Cathal Brugha Street, Dublin 1, Ireland
}

\section{A R T I C L E I N F O}

\section{Keywords:}

Dipyrromethane

Multiple sclerosis

Molecular modeling

Neuronal Kv1 channels

SAR analysis

Selective blocker design

\begin{abstract}
A B S T R A C T
Members of the voltage-gated $\mathrm{K}^{+}$channel subfamily (Kv1), involved in regulating transmission between neurons or to muscles, are associated with human diseases and, thus, putative targets for neurotherapeutics. This applies especially to those containing Kv1.1 a subunits which become prevalent in murine demyelinated axons and appear abnormally at inter-nodes, underlying the perturbed propagation of nerve signals. To overcome this dysfunction, akin to the consequential debilitation in multiple sclerosis (MS), small inhibitors were sought that are selective for the culpable hyper-polarising $\mathrm{K}^{+}$currents. Herein, we report a new semi-podand - compound 3 - that was designed based on the modelling of its interactions with the extracellular pore region in a deduced Kv1.1 channel structure. After synthesis, purification, and structural characterisation, compound $\mathbf{3}$ was found to potently $\left(\mathrm{IC}_{50}=8 \mu \mathrm{M}\right)$ and selectively block Kv1.1 and 1.6 channels. The tested compound showed no apparent effect on native Nav and Cav channels expressed in F-11 cells. Compound 3 also extensively and selectively inhibited MS-related Kv1.1 homomer but not the brain native Kv1.1- or 1.6-containing channels. These collective findings highlight the therapeutic potential of compound 3 to block currents mediated by Kv1.1 channels enriched in demyelinated central neurons.
\end{abstract}

\section{Introduction}

Voltage-gated $\mathrm{K}^{+}$channels of the Shaker subfamily (Kv1) are key players in controlling neuronal excitability and synaptic transmission. Hence, their alteration by either mutation or expression levels is associated with an array of human diseases referred to as $\mathrm{K}^{+}$channelopathies [1-3]. Kv1 channels are tetrameric $\left(\alpha_{4} \beta_{4}\right)$ sialoglycoproteins $(\mathrm{Mr} \sim 400 \mathrm{kDa})$ and were first purified from mammalian brain using polypeptide blockers, $\alpha$ dendrotoxin $(\alpha \mathrm{DTX})$ or dendrotoxin $\mathrm{K}\left(\mathrm{DTX}_{\mathrm{K}}\right)$ $[4,5]$. When expressed in vitro, each of the major Kv1 $\alpha$ subunit genes [Kv1.1-1.8] form homo-tetrameric channels exhibiting distinct biophysical and pharmacological profiles [6]. In vivo, neuronal Kv1 channels are located along the axons mainly as hetero-tetramers and their kinetics as well as patterns of expression are modulated by cytoplasmically-associated auxiliary $\beta$ proteins [7-9]. Only a subset of the possible oligomeric combinations of Kv1 channels has been isolated from mammalian brain, including humans [10-13]. This suggests that native synthesis and/or assembly are restricted. Among all Kv1 channels expressed in neuronal membranes, the Kv1.2 is the most prevalent in forming heterotetramers with other Kv1 a subtypes (mainly with Kv1.1 and to a lesser extent with Kv1.4 and 1.6) or, in smaller proportions, as homomeric Kv1.2 channels [10,13] Noticeably, there is preponderance in these preparations of the less abundant Kv1.1 subunit in oligomers with Kv1.2.

The voltage-dependent delayed-rectifier members of the Kv1 channel family play an important role in rapid restoration of the neuronal resting membrane potential, after depolarization. Both Kv1.1 and 1.2 channels are considered low-voltage-activated channels that open with small depolarizations at or below resting potential $[14,15]$. Nevertheless, the homomeric Kv1.1 channels expressed in mammalian cells activates at more negative potentials compared with its Kv1.2 counterparts $[16,17]$. This shift was confirmed when Kv1.1 $\alpha$ subunits were sequentially substituted with Kv1.2 subunits [18]. Such a difference in the voltage-dependence of activation of Kv1.1 and 1.2 would confer the rapid conduction of high-frequency action potentials exhibited between neurons $[19,20]$. Therefore, dysfunction or absence of

\footnotetext{
* Corresponding author.

E-mail address: Kieran.Nolan@dcu.ie (K. Nolan).
} 
Kv1.1 and 1.2 subtypes, in particular Kv1.1, is associated with various neurological disorders including epilepsy and episodic ataxia [2].

Kv1 members exposed on demyelinated axons in patients suffering from multiple sclerosis (MS) contribute to abnormal propagation of nerve signals resulting in debilitating muscle weakness $[6,16] . \mathrm{K}^{+}$ channels containing Kv1.1 and Kv1.2 $\alpha$ subunits have been found to be abnormally over-expressed outside the nodes of Ranvier in demyelinated axons of optic nerve, from a cuprizone-induced mouse model of MS [16]; importantly, the associated abnormal conductivity could be near-normalised by attenuating the Kv1.1-mediated currents with DTX $_{\mathrm{K}}$. These findings guided our efforts to develop a small, extracellular inhibitor (compound 1) targeting such $\mathrm{K}^{+}$channels to ameliorate MS-related symptoms [21]. These results indicate that up to two compounds could interact in the outer pore of Kv1 channels. Herein, analysis of structure-activity relations (SAR) led to the design of a new candidate (compound 3 ), a dimer of compound $\mathbf{1}$, which was shown electrophysiologically to be most potent on Kv1.1 homomeric channels like those in a rodent MS model.

\section{Results and discussion}

\subsection{Rational design of compound 3}

In our earlier work [21], [2,2'-((5,5'(di-p-topyldiaryldi-(2-pyrrolyl) methane)bis(2,2'carbonyl)bis (azanediyl)) diethaneamine.2HCl] (compound 1) (Fig. 1) was identified and characterised as a candidate to specifically block the extracellular pore of a homomeric Kv1.1 channel. It was shown to selectively inhibit this protein, recombinantly expressed in mammalian cells, with an $\mathrm{IC}_{50} \sim 15 \mu \mathrm{M}$, to induce a positive shift in the voltage-dependency of the $\mathrm{K}^{+}$current activation and slow its kinetics. Also, channels containing two or more Kv1.1 $\alpha$ subunits proved susceptible to compound 1. Results of modelling investigations predicted a high number of localized interactions between compound $\mathbf{1}$, the selectivity filter and inner turret region residues of the channel. However, these studies highlighted an issue that compound 1 cannot take full advantage of all these important interactions with residues within the channel due to size constraints. Accordingly, the Hill slope observed for compound $\mathbf{1}$ in our earlier investigation [21] lay between 1.5 and 1.7, indicating that two molecules may be binding to the Kv1.1 channel. This observation led us to consider the possibility of covalently linking two dipyrromethane subunits together (as in the postulated compound 2, Fig. 1) at the para positions of $\mathbf{1}$, in the hope of enhancing selectivity and binding efficiency. However, initial attempts to introduce a reactive group at the para position in the phenyl groups of the dipyrromethane scaffold in compound 1, proved unsuccessful. Further efforts failed to introduce functionality into the carboxylic acid of the dipyrromethane scaffold via condensation with various substituted benzophenone derivatives and pyrrole. Hence, a convenient synthetic route to compound $\mathbf{2}$ was not available.

An alternative new molecule, compound 3, outlined in Fig. 2, was proposed. It would possess the required two dipyrromethane moieties within the structure that are linked with a rigid isophthaloyl amide linker; the latter should reduce the degree of freedom of rotation of the dipyrromethanes relative to each other. There are a series of key structural and functional differences between the proposed compound $\mathbf{3}$ and the putative compound 2 (Figs. 1 and 2) including the replacement of one of the phenyl groups in the dipyrromethanes of compound 2 with a methyl group in compound 3 . This proposed change should not significantly affect binding since the previous modelling of compound 1 with Kv1.1 demonstrated that only one of the tolyl groups made direct $\pi-\pi$ interactions with Tyr 379 , whilst the second tolyl remained on the peripheral region of the pore (see 2-D plot in [21]). Thus, removal of one of the tolyl substituents from compound $\mathbf{1}$ in theory should not disrupt its interaction with the protein. The substitution of the para methyl group in the phenyl ring in compound $\mathbf{2}$ with an amide nitrogen in compound $\mathbf{3}$ is a second change in the sub-structure of the dipyrromethane. To determine if the latter would be a viable candidate, docking with Kv1.1 was undertaken, using the homology models previously employed for compound 1 .

Modelling (see Fig. 3a) revealed that the proposed isophthaloyl amide linker positions the two dipyrromethanes of compound $\mathbf{3}$ into the centre of the pore region of the channel, thereby, spatially aligning these two moieties against the corresponding residues in the protein matrix. Perhaps, the most interesting discovery from the modelling of compound 3 interacting with Kv1.1 is that, unlike our previously reported lead compound $\mathbf{1}$, compound $\mathbf{3}$ shows proximity to Tyr 379 on all the chains. Since Tyr 379 is unique to Kv1.1 and absent from Kv1.2 -1.6 , this intimate interaction observed with compound 3 should result in its enhanced selectivity for Kv1.1 over the other channels.

The ligand plot (Fig. 3b) indicates all the molecule-protein interactions predicted for compound 3 with Kv1.1. A major observation made from the ligand plot is the optimal hydrogen bonding (HB) between the Tyr379 and both the amide plus the terminal amine moiety of the side group of compound 3 (Fig. 3b). More detailed analysis of the modelling of compound 3 with the previously established rat Kv1.1 homology model (Fig. 3a) confirmed that the presence of a single phenyl unit in the dipyrromethanes could be sufficient for direct $\pi-\pi$ interactions with Tyr 379 in the channel. Furthermore, there was also

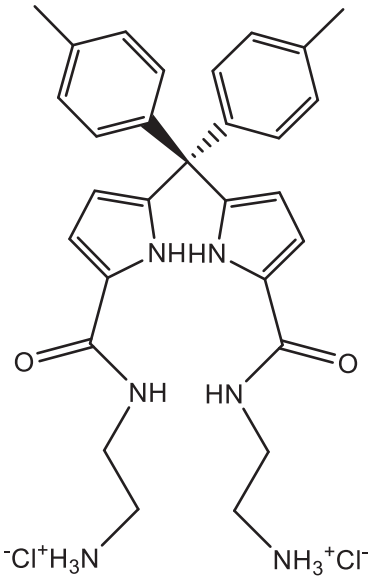

1

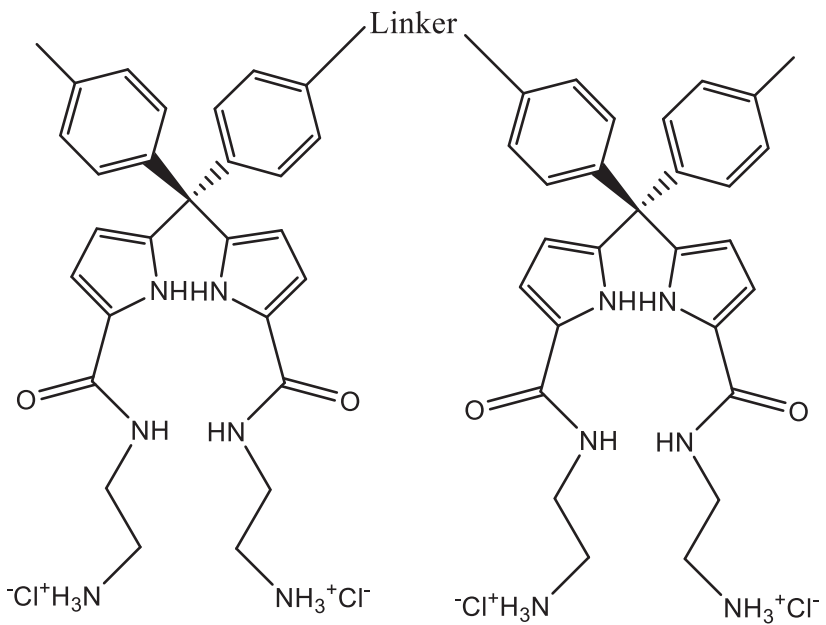

2

Fig. 1. The structure of compound 1 and that proposed for compound 2 . 


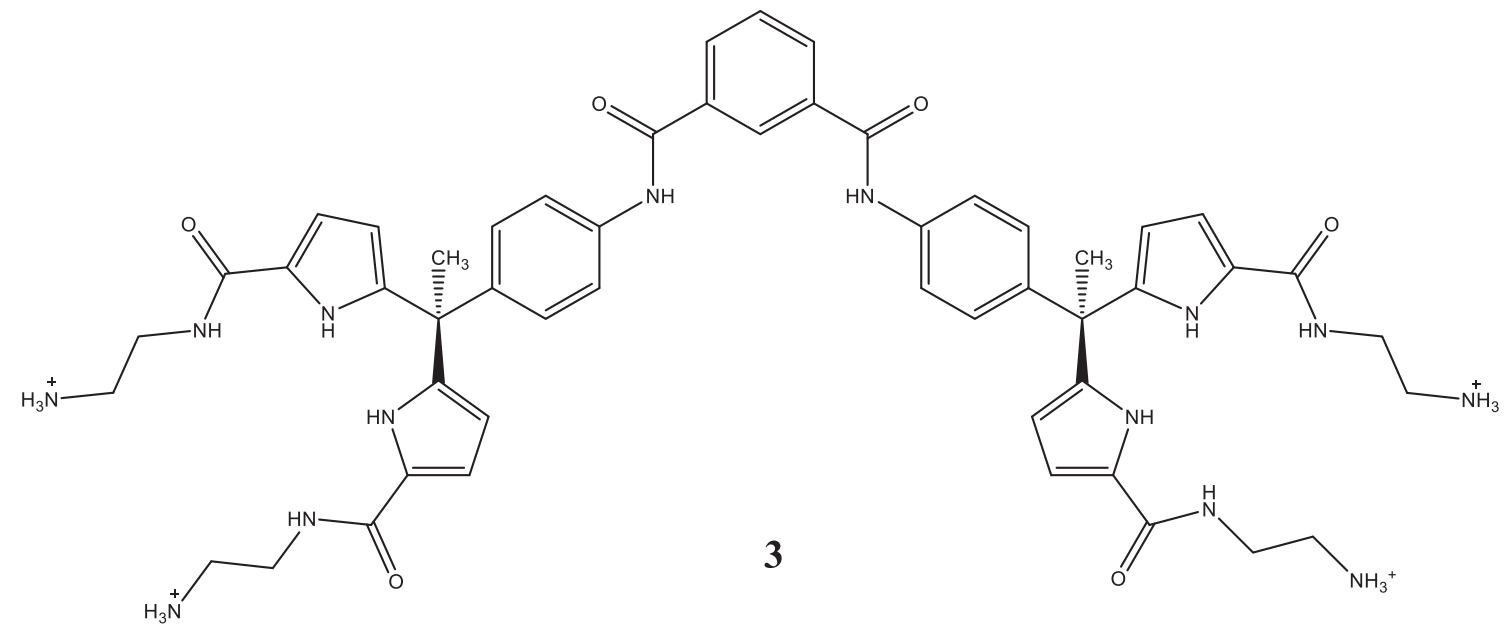

Fig. 2. Schematic structure of the new semi-podand N,N'bis isophthalamide, compound 3.

strong interaction between the terminal amine groups of compound $\mathbf{3}$ and the Asp 377 residues on two of the chains (A and B) and a potential HB between compound 3 and Tyr 375 on one of the chains (C).

\subsection{Synthesis and purification of compound 3}

The synthetic route for the preparation of compound $\mathbf{3}$ is outlined in Scheme 1. The first step involved the coupling of isophthaloyl chloride (4) with 4-aminoacetophenone (5), using TEA in THF at room temperature to give compound 6 in $85 \%$ yield. Condensation of compound 6 with pyrrole was initially performed using the published procedure [21] that involves $\mathrm{BF}_{3} \cdot(\mathrm{OEt})_{2}$ in methanol; unfortunately, only trace quantities of compound $\mathbf{7}$ were formed. The yield of the latter was increased by condensing compound 6 in freshly distilled-pyrrole with trifluoroacetic acid $\left(12 \%\right.$ volume in place of $\left.\mathrm{BF}_{3} \cdot(\mathrm{OEt})_{2}\right)$ at $70{ }^{\circ} \mathrm{C}$ over four hours; this gave $28 \%$ recovery of compound 7 after repeated chromatography. Conversion of compound 7 to 8 was achieved by treating the former with trichloroacetic anhydride (TClAA) and DMAP in $\mathrm{CH}_{2} \mathrm{Cl}_{2}$ to give the final product in $68 \%$ yield, after chromatography.
The final two steps in the synthesis of compound $\mathbf{3}$ involved treating compound 8 with $\mathrm{N}$-Boc ethylenediamine (5 equivalents) in anhydrous $\mathrm{CH}_{2} \mathrm{Cl}_{2}$ at $0{ }^{\circ} \mathrm{C}$ to which 4 equivalents of TEA were added dropwise. After addition, the solution was allowed to heat to room temperature and stirred overnight. The resultant precipitate was filtered and washed thoroughly with both diethyl ether and $\mathrm{CH}_{2} \mathrm{Cl}_{2}$. The collected precipitate was then suspended in anhydrous $\mathrm{CH}_{2} \mathrm{Cl}_{2}$ at $0{ }^{\circ} \mathrm{C}$ and $4 \mathrm{M} \mathrm{HCl}$ in dioxane was added dropwise at $0{ }^{\circ} \mathrm{C}$. Once the addition was complete, the reaction was allowed to stir overnight at room temperature. The resulting precipitate formed during the reaction was isolated by filtration and washed with diethyl ether to give compound 3 in $84 \%$ yield. Its structural characterisation is detailed in the Appendix (Supplementary data)

\subsection{Preferential selectivity and potent blockade by compound 3 of homomeric Kv1.1 and Kv1.6 channels but not a Kv1.6 - containing heteromer}

To measure the reactivity of compound 3 with Kv1 channels, those containing the major $\alpha$ subunits found in the mammalian brain $[6,13]$ (a)

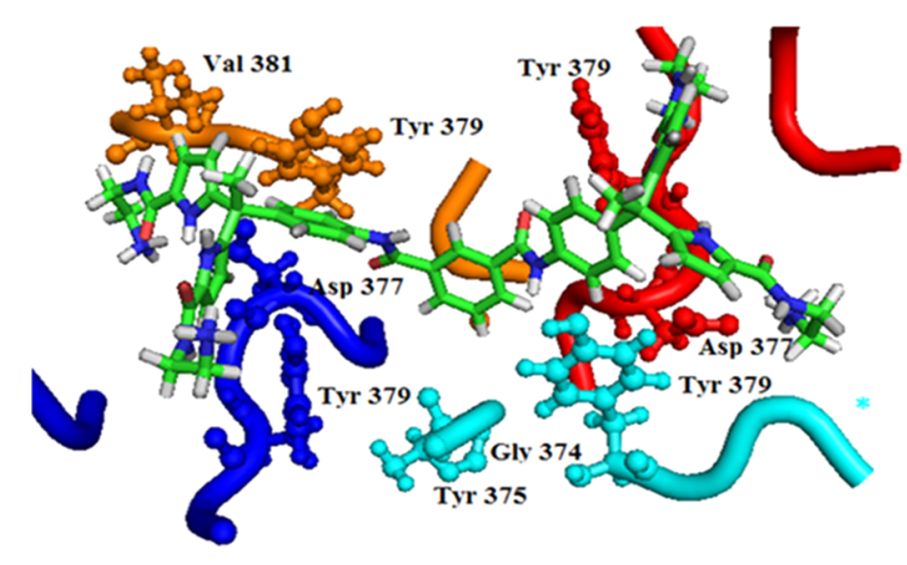

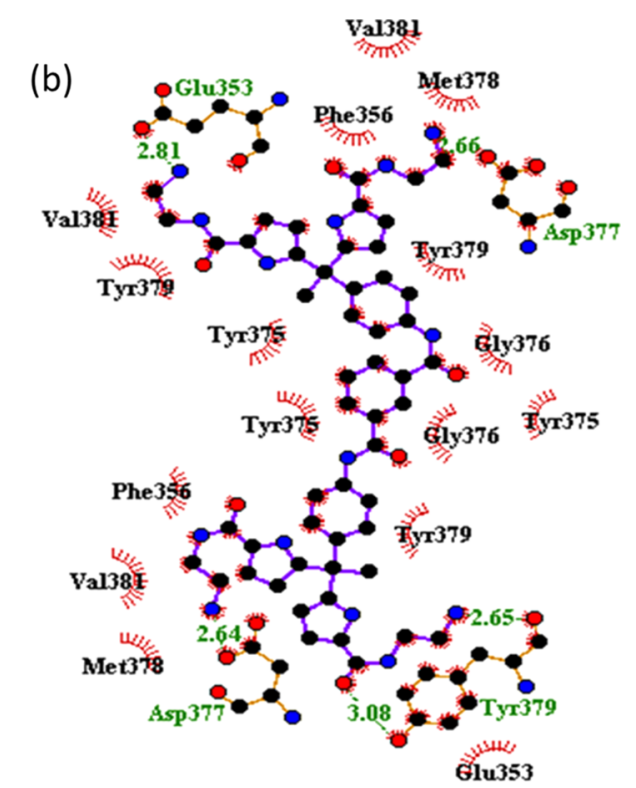

Fig. 3. A docked model of compound 3 with the pore region of Kv1.1 channel. (a) Compound $\mathbf{3}$ (in green) docked into the rat Kv1.1 homology model. Red illustrates chain A, blue relates to chain B, cyan indicates chain C and orange is chain D of the subunits. The image was generated using Pymol (The PyMOL Molecular Graphics System). (b) 2D ligand-plot of compound 3 docked onto the rat Kv1.1 homology model, illustrating the deduced interactions with numbered amino acids in the channel protein, generated by LigPlot ([22] 
<smiles>CC(=O)c1ccc(NC(=O)c2cccc(C(=O)Nc3ccc(C(C)=O)cc3)c2)cc1</smiles>

(iv)

\section{8}<smiles>CC(c1ccc(NC(=O)c2cccc(C(C)(c3ccc(C(=O)C(F)(F)F)[nH]3)c3ccc(C(=O)C(F)(F)F)[nH]3)c2)cc1)(c1ccc(NC(=O)c2ccc(C(=O)C(F)(F)C(F)(F)Cl)[nH]2)cc1)c1ccc(C(=O)C(F)(F)Cl)[nH]1</smiles>

(v)

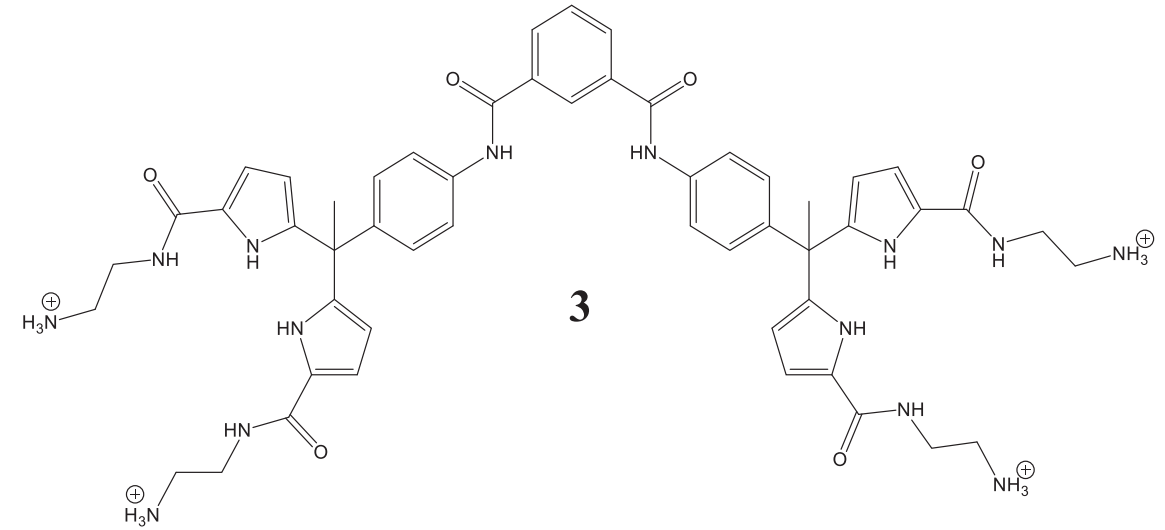

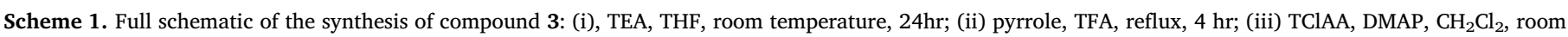
temperature; (iv) $\mathrm{N}$-Boc ethylenediamine, TEA, $\mathrm{CH}_{2} \mathrm{Cl}_{2}$, room temperature and (v) $4 \mathrm{M} \mathrm{HCl}$ in dioxane $\mathrm{CH}_{2} \mathrm{Cl}_{2}$ room temperature.

were expressed in HEK-293 cells and their $\mathrm{K}^{+}$currents recorded, using whole-cell voltage patch-clamp (Fig. $4 \mathrm{a}$ and $\mathrm{b}$ ).

Representative $\mathrm{K}^{+}$current traces, in the absence or presence of $10 \mu \mathrm{M}$ compound 3 , revealed a considerable inhibition of Kv1.1 $(69 \pm 1 \%, n=6)$ and a lesser extent for Kv1.3 (11 $\pm 2 \%, n=4)$ channels whilst being ineffective towards Kv1.2 or 1.4 homomers. Also, the Kv1.6-mediated current was reduced by $10 \mu \mathrm{M}$ compound 3 (62 $\pm 11 \%, n=3$ ), close to that of Kv1.1, but not by compound 1 . However, compound $\mathbf{3}$ proved unable to inhibit a transiently expressed heteromeric channel possessing one copy of Kv1.6 subunit (Kv1.4-1.2-1.2-1.6, Fig. 4a) which mimic those present in neurons $[6,13,23]$.

The dose-dependence for the blockade of Kv1.1 by compound 3 revealed an $\mathrm{IC}_{50}$ value of $8 \pm 0.4 \mu \mathrm{M}(\mathrm{n}=6)$; a Hill slope of $1.1 \pm 0.1$ indicates only unimolecular binding between the channel and compound 3 . These results illustrate that a single molecule of compound $\mathbf{3}$ is solely interacting with the tetramer channel, thus, validating our earlier hypothesis. The comparative results seen with compound $\mathbf{3}$ and the previously reported compound $\mathbf{1}$ are highly interesting; compound 3 is almost twice as potent for the Kv1.1 channel than the smaller compound 1, again in accordance with our earlier prediction [21]. Moreover, compound $\mathbf{3}$ displayed a lower level of inhibition of Kv1.3 compared to compound 1. This outcome is noteworthy because the ratio of the extent of inhibition by compound 1 under the same conditions for Kv1.1 and Kv1.3 channels was reported as 1 this has increased to $\sim 4$ for compound 3 . Notably, the inhibitory effect of compound 3 on the Kv1.1 channel is associated with significant slowing of its activation kinetics $[\sim 16$ times; $2 \pm 0.1 \mathrm{~ms}$ before and $33 \pm 2.3 \mathrm{~ms}$ after $10 \mu \mathrm{M}$ compound $3, \mathrm{P}<0.001 \mathrm{n}=4$, respectively] [see current traces in Fig. 4(a)]. In comparison, compound 3 showed a lower decrease in the activation kinetics of Kv1.3-mediated currents $\sim 11$ times $[1.42 \pm 0.01 \mathrm{~ms}$ before and $1.6 \pm 0.07 \mathrm{~ms}$ after 
(a)

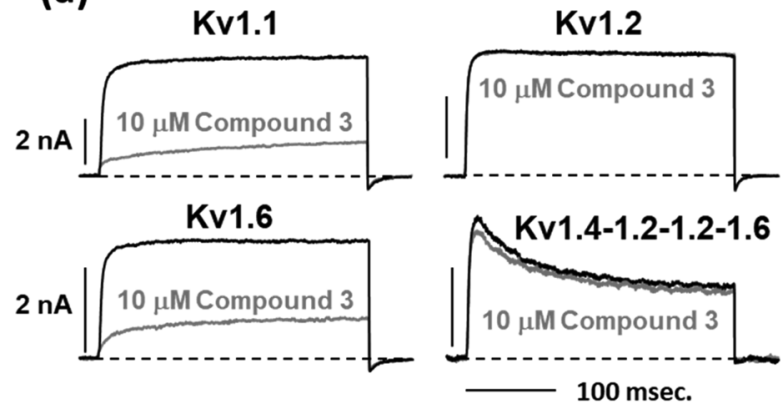

(c)

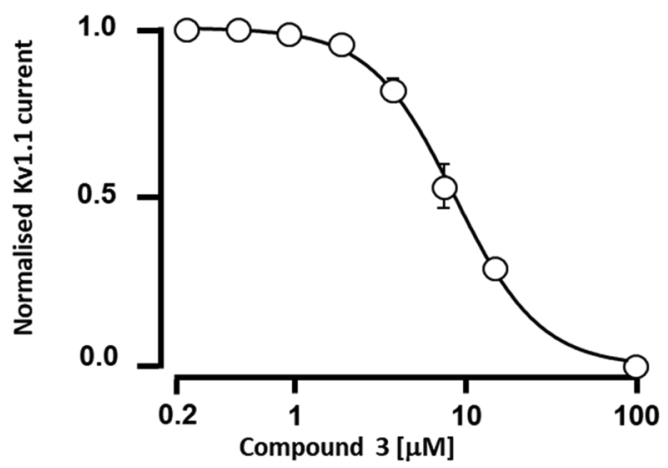

(b)

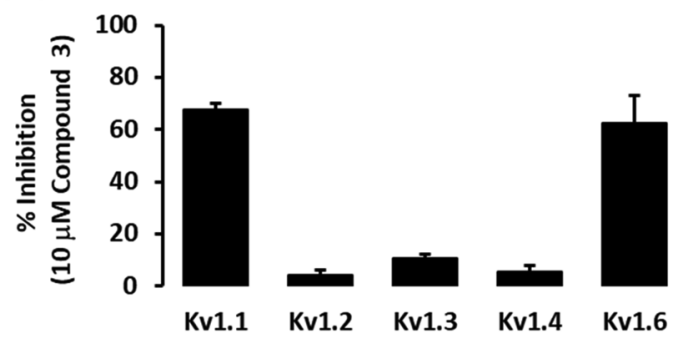

(d)

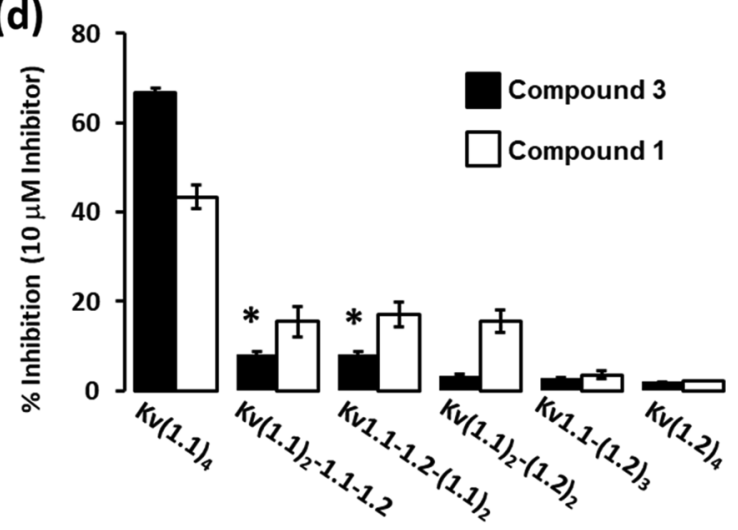

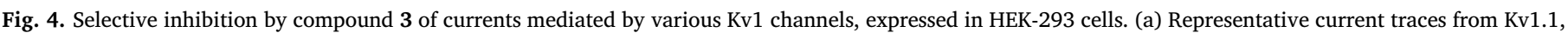

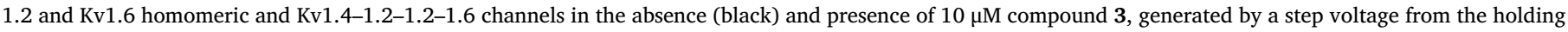

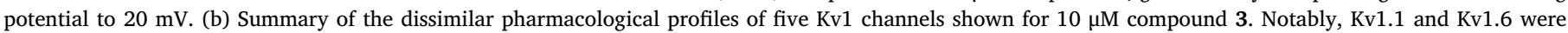

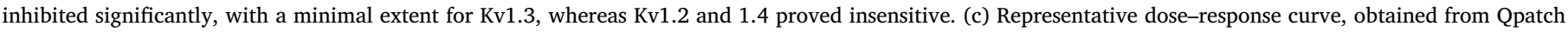

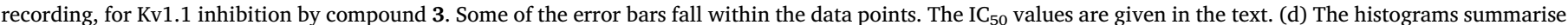
the selectivity of compound $3\left(10 \mu \mathrm{M}\right.$; filled bars) over compound 1 in inhibiting each $\mathrm{K}^{+}$current.

\section{a} Control $\quad 100 \mu \mathrm{M} \mathrm{Cd}^{2+} /[\mathrm{Cs}]_{\mathrm{i}}$
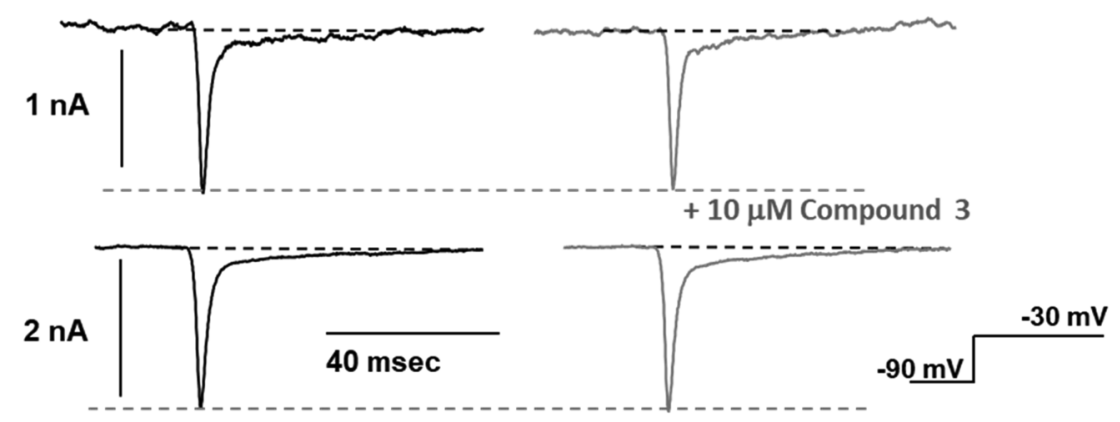

b

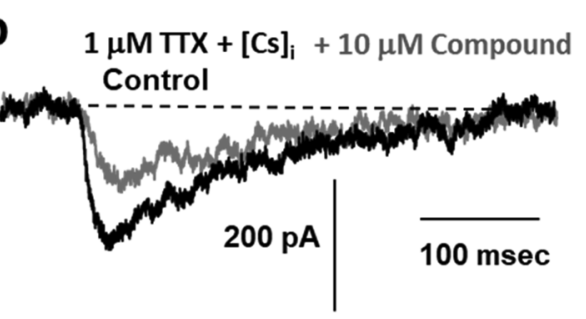

$+10 \mu \mathrm{M}$ Compound 3

$+10 \mu \mathrm{M}$ Candidate I

$+10 \mu \mathrm{M}$ Compound 3

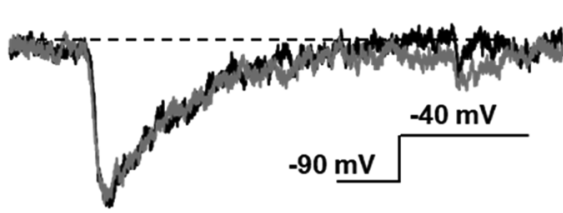

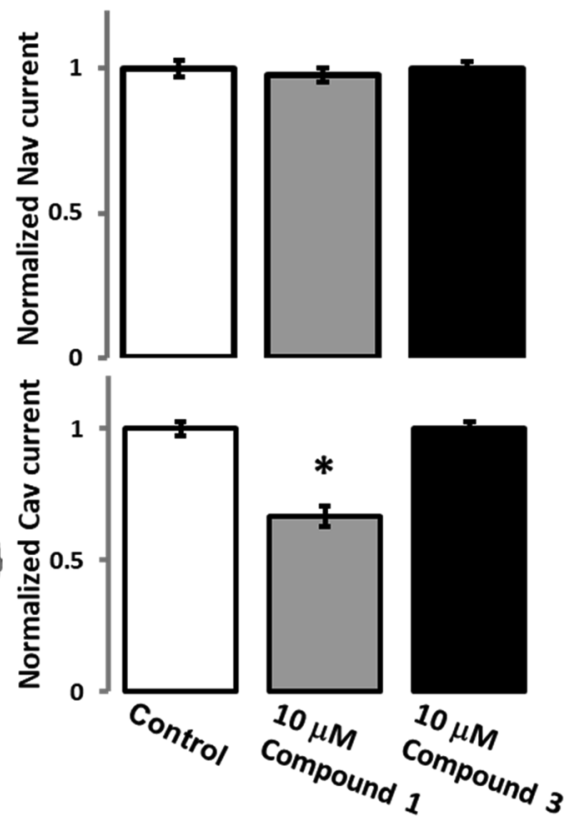

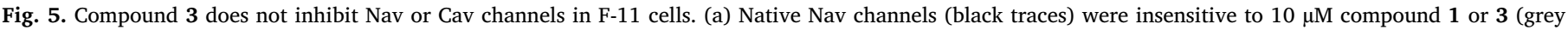

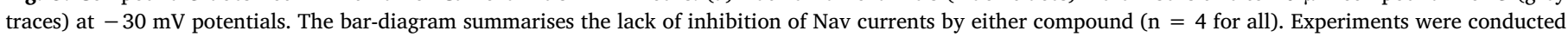

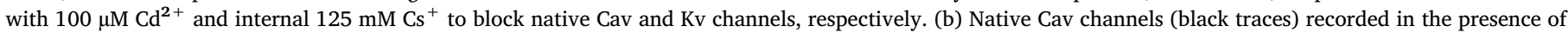

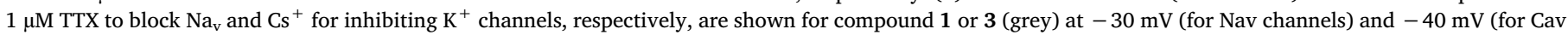

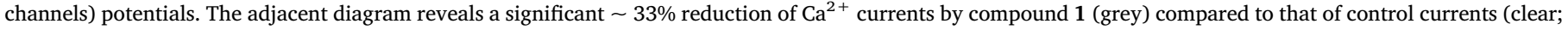
$\mathrm{P}<0.001, \mathrm{n}=4$ for all), and the absence of any inhibition of Cav currents by compound 3 (black). 
$10 \mu \mathrm{M}$ compound $3, \mathrm{P}=0.0646, \mathrm{n}=3$, respectively]. These data reveal the notably similar inhibition pattern, particularly the slowing of activation kinetics by compounds $\mathbf{3}$ and $\mathbf{1}$ [21] with more prominent inhibition exerted by compound 3 .

Next, concatenated Kv1.1 and/or Kv1.2 channels were evaluated for inhibition by compound 3 of Kv1 channels (Fig. 4d) resembling those in demyelinated neurons ([16] in comparison to compound 1. Only Kv1.1 homo-tetramers and some heteromeric Kv1.1-enriched channels (those with 3 copies of Kv1.1) are inhibited regardless of their arrangement in the tetramer. Notice a significant difference between the blockade by compound 3 of homo-tetrameric Kv1.1 channel [66 $\pm 1 \%(\mathrm{n}=3)]$ compared to $\operatorname{Kv}(1.1)_{3}-1.2$ channels [Kv1.1-1.1-1.1-1.2: $8 \pm 1 \%$ $(\mathrm{n}=3)$ and Kv1.1-1.2-1.1-1.1: $8 \pm 0.5 \%(\mathrm{n}=3) ; \mathrm{p}<0.0001$, each]. This compound lacks significant reactivity towards channels with two, one or no copies of Kv1.1 subunit in the tested tetramers [Kv1.1-1.1-1.2-1.2: $3 \pm 0.4 \%(\mathrm{n}=3$ ), Kv1.1-1.2-1.2-1.2: $3 \pm 0.1 \%(\mathrm{n}=3)$ and $\mathrm{Kv} 1.2-1.2-1.2-1.2: 2 \pm 0.1 \%(\mathrm{n}=3)$, respectively]. On the other hand, compound 1 equally inhibits tetrameric channels containing two Kv1.1 subunit [Kv1.1-1.1-1.2-1.2: $15 \pm 2 \%$ $(n=5)]$ or three copies of Kv1.1 subunits irrespective of their positions [Kv1.1-1.1-1.1-1.2: $15 \pm 3 \%(\mathrm{n}=4)$ and Kv1.1-1.2-1.1-1.1: $17 \pm 3 \%(\mathrm{n}=7)]$. Compound 1 showed no apparent inhibition of Kv1.1-1.2-1.2-1.2 channel: $4 \pm 1 \%(\mathrm{n}=4)$ or tetrameric Kv1.2 channel: $2 \pm 0.03 \%(n=4)$. These data reveal that compound 3 is a more selective blocker of homotetrameric Kv1.1 channel compared to its precursor. To evaluate the reactivity of compound $\mathbf{3}$ (in comparison to 1) with Nav and Cav channels, DRG hybridoma cell line (F-11) was used because it is known to be enriched with such channels; these include subtypes concerned with pain transduction: Nav1.6, Nav1.7 and Nav1.8 and most Cav channels (mainly Cav 3.3, 3.2, 2.2, 2.1 and 1.2) [24]. Neither of the candidates inhibited native TTX-sensitive Nav currents (such as Nav 1.6 or Nav 1.7) in F11 cells (Fig. 5a). Only compound 1 showed a partial block of the Cav channels (Fig. 5b).

Collectively, these findings further emphasise the selective nature and specificity of compound $\mathbf{3}$ in blocking Kv1 channels without affecting native neuronal Nav and Cav channels.

As Kv1.1 homotetramers have been found only to be expressed in demyelinated neurons, these channels are considered a promising target for small extracellular blockers to normalize reduced excitability, hence, potentially ameliorate symptoms in MS. In fact, the abnormal conductivity in demyelinated axons were nearly normalized by attenuating the Kv1.1-mediated currents with the available selective blocker $\left(\mathrm{DTX}_{\mathrm{K}}\right)$ of Kv1.1 homotetramers [16]. Unfortunately, the avid $\mathrm{DTX}_{\mathrm{K}}$ peptide toxin cannot be considered as a potential neurotherapeutic. Towards this end, we were encouraged to develop synthetic inhibitors selective for such MS-associated channels. A rational design using SAR analysis led initially to the formation and characterization of compound 1, that showed selectivity for Kv1.1 channels [21]. This encouraged us to suspect that linking two copies of compound 1, in a para position, could enhance selectivity and binding efficiency to regions at the selectivity filter to residues in the inner turret region of the Kv1.1 channel. In the present study, a dimeric form of compound 1, with a covalent linker inserted created the formation of compound 3.

As predicted, compound $\mathbf{3}$ was shown to have double the potency towards Kv1.1 with a Hill slope $\sim 1$, confirming a single molecule binding to a Kv1.1 channel. It is not surprising that compound 3 inhibits Kv1.1 and 1.6 channels since both share similarity in key interacting residues at the inner turret region (Tyr 379 in Kv1.1 and Tyr 429 in Kv1.6). As Kv1.6-enriched channels are not found in native or demyelinated neuronal preparations $[10-13,16]$, such cross-reactivity seen with compound $\mathbf{3}$ should not prove to be an issue. Also, compound $\mathbf{3}$ has no apparent effect on native Nav and Cav channels expressed in F11 cells, unlike compound 1 which exhibited some inhibition of Cav current. This is an advantage of compound 3 in being specific for Kv1.1containing channels and not cross-react with other native ion channels. On the other hand, the dual effect of both compounds, by inhibiting $\mathrm{K}^{+}$ currents and slowing the activation kinetics of blocked channels found to be advantageous in overcoming the hypo-excitability and accelerated the activation kinetics seen in demyelinated optic axons [16]. Interestingly, compound 3, unlike its precursor, showed to be a more selective blocker of homo-tetrameric Kv1.1 than Kv1.1-containing channels (with 1-3 Kv1.1 copies). The therapeutic usage of 4-aminopyridine (4-AP) is limited by being non-selective between Kv1 channel types and causing seizures [25]. Unlike 4-AP, compound 3 is exclusively reactive with Kv1.1 and devoid of the effect on the most prevalent subtype, $\mathrm{Kv} 1.2$; this is an extra advantageous feature especially being selective for those channels only associated with demyelinated neurons, and not natively-expressed varieties in nearby healthy neurons.

\section{Conclusions}

This work demonstrated that the dimeric compound $\mathbf{3}$ is a preferential inhibitor of Kv1.1 channels relative to compound 1. Its design was based on in silico and electrophysiological investigations that established two copies of compound $\mathbf{1}$ are needed to block the extracellular pore region of Kv1.1 channel. This hypothesis was validated by the observation that compound $\mathbf{3}$ displays a more potent and selective blockade of Kv1.1-enriched channels, found in demyelinated neurons (see below). Such inhibition is also associated with slowing the activation kinetics of the channels. Although compound 3 displays twice the inhibitory efficacy of compound 1 on Kv1.1, it also inhibits Kv1.6. The latter seems to result from a key interaction with a Tyr in the inner turret region of Kv1.6, as this same residue also exists in the inner turret of Kv1.1. Fortuitously, homomeric Kv1.6 has not been detectable in brain synaptic membrane [8]. Furthermore, compound $\mathbf{3}$ offers an additional advantage of interacting with heteromeric channels possessing three copies of Kv1.1 or Kv1.1 homomers; importantly, these are the channels shown to be expressed on demyelinated neurons and responsible for their hypo-excitability [16,21]. Moreover, compound 3 does not affect Nav or Cav channels, at least at the $10 \mu \mathrm{M}$ tested. These collective findings highlight the therapeutic potential of compound 3 to block currents mediated by Kv1.1 channels enriched in demyelinated central neurons.

\section{Experimental section}

\subsection{Chemistry}

4.1.1. N1, N3-bis(4-acetylphenyl)-1,3-benzenedicarboxamide compound 6

To a $250 \mathrm{~mL}$ round bottom flask, $4.3 \mathrm{~g}(32.5 \mathrm{mmol})$ of 4-aminoacetophenone (5) was added and dissolved in $45 \mathrm{~mL}$ of anhydrous THF. After adding anhydrous TEA $(2.5 \mathrm{~mL})$, the reaction mixture was chilled to $0{ }^{\circ} \mathrm{C}$ and stirred; isophthaloyl chloride (4) $(3.0 \mathrm{~g} 14.8 \mathrm{mmol})$ was dissolved in $30 \mathrm{~mL}$ of anhydrous THF and added dropwise to the stirred solution. The reaction was stirred for $4 \mathrm{~h}$ before filtering the precipitate. After washing the precipitate with $5 \times 50 \mathrm{~mL} \mathrm{H}_{2} \mathrm{O}$ and $5 \times 50 \mathrm{~mL}$ of $\mathrm{CH}_{2} \mathrm{Cl}_{2}$, it was dried to give 6 as a white solid in $85 \%$ yield $(5.02 \mathrm{~g})$.

${ }^{1} \mathrm{H}$ NMR (400 MHz) $\delta$ (DMSO- $\left.\mathrm{d}_{6}\right) 10.7(2 \mathrm{H}, \mathrm{s}, \mathrm{NH}) 8.5(1 \mathrm{H}, \mathrm{s}, \mathrm{CH})$ $8.1(2 \mathrm{H}, \mathrm{m}, \mathrm{CH}) 7.9(8 \mathrm{H}, \mathrm{dd}, \mathrm{p}-\mathrm{Phenyl}-\mathrm{H}) 7.7(1 \mathrm{H}, \mathrm{t}, \mathrm{CH}) 2.4(6 \mathrm{H}, \mathrm{s}$, $\left.\mathrm{CH}_{3}\right){ }^{13} \mathrm{C}$ NMR (100 MHz, DMSO- $\mathrm{d}_{6}$ ) 196.6, 165.4, 143.4, 134.8, 132.1, $131.1,129.3,128.8,127.2,119.5,26.5$.

\subsubsection{Compound 7}

To a $100 \mathrm{~mL}$ round bottom flask, $1 \mathrm{~g}(2.49 \mathrm{mmol})$ of 6 was added, followed by $15 \mathrm{~mL}$ (216 mmol) of freshly-distilled pyrrole. TFA $(2 \mathrm{~mL})$ was added dropwise and stirred at $70{ }^{\circ} \mathrm{C}$ for $4 \mathrm{~h}$. The reaction was quenched with $5 \mathrm{~mL}$ of TEA and stirred at room temperature for 20 mins. Unreacted pyrrole was removed under high vacuum at $50{ }^{\circ} \mathrm{C}$ to leave a black tar-like oil. The crude reaction mixture was purified twice by silica gel chromatography, eluted with hexane: ethyl acetate (3:2); after removal of the solvent under reduced pressure, compound 7 was obtained as a beige solid in $28 \%$ yield ( $450 \mathrm{mg}$ ). 
${ }^{1} \mathrm{H}$ NMR (400 MHz) $\delta$ (DMSO- $\left.\mathrm{d}_{6}\right) 10.4(6 \mathrm{H} \mathrm{m}, \mathrm{NH}$ pyrrole $+\mathrm{NH}$ amide) $8.5(1 \mathrm{H}, \mathrm{s}, \mathrm{CH}) 8.1(2 \mathrm{H}, \mathrm{m}, \mathrm{CH}) 7.7(5 \mathrm{H}, \mathrm{d}$, phenyl-H + $\mathrm{CH}) 7.0$ $(4 \mathrm{H}, \mathrm{d}$, phenyl-H) $6.7(4 \mathrm{H}, \mathrm{m}$, pyrrole- $\mathrm{H}) 5.9(4 \mathrm{H}, \mathrm{s}$, pyrrole- $\mathrm{H}) 5.6(4 \mathrm{H}$, m, pyrrole-H) $2.0\left(6 \mathrm{H}, \mathrm{s}, \mathrm{CH}_{3}\right)^{13} \mathrm{C}$ NMR $\left(100 \mathrm{MHz}\right.$, DMSO- $\left.\mathrm{d}_{6}\right) 165.8$, 145.2 , 138.7, 137.9, 136.1, 131.5, 129.5, 128.3, 127.9, 120.4, 118.1, $107.2,106.8,44.8,28.9$

\subsubsection{Compound 8}

To a $50 \mathrm{~mL}$ round bottom flask, $200 \mathrm{mg}(0.316 \mathrm{mmol})$ of compound 7 was added with $18 \mathrm{mg}(0.158 \mathrm{mmol})$ of DMAP. These were suspended in $10 \mathrm{~mL}$ anhydrous $\mathrm{CH}_{2} \mathrm{Cl}_{2}$, chilled to $0{ }^{\circ} \mathrm{C}$ and placed under an argon atmosphere. To this mixture was added dropwise $0.288 \mathrm{~mL}$ $(1.58 \mathrm{mmol})$ of trichloroacetic anhydride and the reaction mixture allowed to stir at room temperature for $2 \mathrm{~h}$. The reaction was then stopped by the addition of aqueous $\mathrm{NaHCO}_{3}$ and the organic layer washed with brine $(2 \times 10 \mathrm{~mL})$; the organic layer was dried over $\mathrm{MgSO}_{4}$ and the solvent removed under reduced pressure. The resulting crude product was then purified by silica gel column chromatography, eluting with ethyl acetate and hexane (1:3) to give 8 as a white solid in $68 \%$ yield $(0.2614 \mathrm{~g})$.

${ }^{1} \mathrm{H}$ NMR (400 MHz) $\delta$ (DMSO- $\mathrm{d}_{6}$ ) 12.2 (4H, s, NH-pyrrole) 10.5 $(2 \mathrm{H}, \mathrm{s}, \mathrm{NH}$-amide) $8.5(1 \mathrm{H}, \mathrm{s}, \mathrm{CH}) 8.1(2 \mathrm{H}, \mathrm{m}, \mathrm{CH}) 7.8-7.7(5 \mathrm{H}, \mathrm{d}$, phenyl-H + $\mathrm{CH}) 7.3(4 \mathrm{H}, \mathrm{m}$, pyrrole- $\mathrm{H}) 7.0(4 \mathrm{H}, \mathrm{d}$, phenyl-H) $6.1(4 \mathrm{H}$, m, pyrrole- $\mathrm{H}) 2.1\left(6 \mathrm{H}, \mathrm{s}, \mathrm{CH}_{3}\right){ }^{13} \mathrm{C}$ NMR $\left(100 \mathrm{MHz}\right.$, DMSO- $\left.\mathrm{d}_{6}\right) 171.8$, 165.0, 147.8, 141.0, 137.7, 135.0, 130.7, 128.6, 127.3, 127.0, 122.3, 121.2, 120.4, 111.3, 95.3, 45.2, 27.5.

\subsubsection{Compound 3}

To a $25 \mathrm{~mL}$ round bottom flask was added $150 \mathrm{mg}(0.125 \mathrm{mmol})$ of 8 and $5 \mathrm{~mL}$ of anhydrous $\mathrm{CH}_{2} \mathrm{Cl}_{2}$; the mixture was placed under an argon atmosphere. To this was added dropwise $0.094 \mathrm{~mL}(0.592 \mathrm{mmol})$ of $N$-Boc ethylenediamine and the reaction mixture allowed to stir for 10 mins. Anhydrous TEA $(0.082 \mathrm{~mL}, 0.592 \mathrm{mmol})$ was then added and the mixture stirred for $24 \mathrm{~h}$ at room temperature under an argon atmosphere. The resulting precipitate was vacuum filtered using a glass frit and washed thoroughly with $\mathrm{CH}_{2} \mathrm{Cl}_{2}$ to give a white/beige solid $(144 \mathrm{mg})$. This precipitate $(100 \mathrm{mg})$ was placed in a $25 \mathrm{~mL}$ round bottom flask, followed by the addition of $5 \mathrm{~mL}$ of anhydrous $\mathrm{CH}_{2} \mathrm{Cl}_{2}$; the mixture was then placed under an argon atmosphere and chilled to $0{ }^{\circ} \mathrm{C}$. After the addition of $1 \mathrm{~mL}$ of $4 \mathrm{M} \mathrm{HCl}$ in dioxane was complete (addition is done at $0{ }^{\circ} \mathrm{C}$ ), the reaction was left stirring for $24 \mathrm{~h}$ at room temperature. The precipitate that formed was vacuum filtered and washed with $\mathrm{CH}_{2} \mathrm{Cl}_{2}$ to give compound 3 in $84 \%$ yield.

${ }^{1} \mathrm{H}$ NMR (400 MHz) $\delta$ (DMSO- $\mathrm{d}_{6}$ ) 11.2 (4H, s, NH-pyrrole) 10.6 $(2 \mathrm{H}, \mathrm{s}, \mathrm{NH}$-amide) $8.7(1 \mathrm{H}, \mathrm{s}, \mathrm{CH}) 8.3(4 \mathrm{H}, \mathrm{t}, \mathrm{NH}$-amide $) 8.1(2 \mathrm{H}, \mathrm{m}$, CH) $8.0\left(12 \mathrm{H}, \mathrm{s}, \mathrm{NH}_{3}{ }^{+}\right) 7.7(5 \mathrm{H}, \mathrm{d}$, phenyl-H $+\mathrm{CH}) 6.9(4 \mathrm{H}, \mathrm{d}$, phenylH) $6.7(4 \mathrm{H}, \mathrm{m}$, pyrrole- $\mathrm{H}) 5.9(4 \mathrm{H}, \mathrm{m}$, pyrrole- $\mathrm{H}) 3.3\left(8 \mathrm{H}, \mathrm{m}, \mathrm{CH}_{2}\right) 2.9$ $\left(8 \mathrm{H}, \mathrm{m}, \mathrm{CH}_{2}\right) 2.0\left(6 \mathrm{H}, \mathrm{s}, \mathrm{CH}_{3}\right)$

HR-MALDI MS: Calculated (M-4HCl: 976.4820) Observed (M + 14HCl: 977.4899)

\subsection{Molecular biology}

\subsubsection{DNA constructs}

cDNAs for rat Kv1.1. 1.2, 1.3, 1.4 and 1.6 were kindly provided by Professor Olaf Pongs (Institute for Neural Signal Transduction, University of Hamburg, Germany). Concatenation of four $\alpha$ Kv1.1 and/ or Kv1.2, Kv1.4 with Kv1.2 and Kv1.6 subunits as a single ORF was accomplished using an inter-subunit linker derived from the untranslated regions (UTRs) of the Xenopus $\beta$-globin gene (GenBank ${ }^{\circledast}$ accession number J00978) $[26,27]$ as reported previously [21]

\subsubsection{Expression of Kv1 channels in HEK293 cells}

Kv1.1, 1.2, 1.3, 1.4, and 1.6, Kv1.1-homotetramers, Kv1.2-homotetramers, Kv1.1-1.2-1.1-1.1, Kv1.1-1.1-1.1-1.2, Kv1.1-1.1-1.2-1.2, and Kv1.1-1.2-1.2-1.2 channels were stably expressed in HEK-293 cells (American Type Culture Collection) [21]. Kv1.4-1.2-1.2-1.6 channel [23]. was transiently transfection into HEK-293 cells using Trans-293 ${ }^{\circledR}$ transfection reagent (Mirus Bio LLC, Madison, WI, USA).

\subsubsection{Electrophysiological recordings and data analysis}

Whole-cell voltage clamp was performed as previously outlined $[18,28]$, except where specified. In the conventional patch clamp system [EPC10 amplifier (HEKA Elektronik, Lambrecht/Pfalz, Germany)], the recording pipette was filled with an internal solution that contained (in mM): $95 \mathrm{KF}, 30 \mathrm{KCl}, 1 \mathrm{CaCl}_{2}, 1 \mathrm{MgCl}_{2}, 11 \mathrm{EGTA}, 10$ HEPES, $2 \mathrm{~K}_{2} \mathrm{ATP}$ ( $\mathrm{pH} 7.2$ with $\mathrm{KOH}$ ), having fire-polished tips of resistances between 2 and $5 \mathrm{M} \Omega$. Composition of the external (bath) medium (in mM) was: $135 \mathrm{NaCl}, 5 \mathrm{KCl}, 2 \mathrm{CaCl}_{2}, 2 \mathrm{MgCl}_{2}$, and $5 \mathrm{Hepes}$, and 10 sucrose (pH 7.4 with $\mathrm{NaOH})$. A correction was made for liquid junction potential $(+7 \mathrm{mV})$. Leakage and capacitive currents were subtracted on-line using the $\mathrm{P} / 4$ subtraction protocol. Currents were filtered at $1 \mathrm{kHz}$ and sampled at $10 \mathrm{kHz}$. Only cells with a $\mathrm{K}^{+}$current $\left(\mathrm{I}_{\mathrm{K}}\right)$ of $>1 \mathrm{nA}$ were chosen for experimentation, to avoid interference from endogenous outward currents $(<200 \mathrm{pA}$ at $+20 \mathrm{mV}$ potential $)$, and having series resistances $<10 \mathrm{M} \Omega$ throughout the experiments. Whole-cell currents were measured at a holding potential of $-90 \mathrm{mV}$, and then depolarized to $+20 \mathrm{mV}$ for $300 \mathrm{~ms}$ or stepped from the holding potential in $+10 \mathrm{mV}$ increments to $+80 \mathrm{mV}$. Currents from the $\mathrm{Kv}$ channels tested were calculated from averaged steady-state currents after $200 \mathrm{~ms}$ of activation. For Kv1.4, currents were determined from the averaged peak after activation.

Automated whole-cell voltage clamp system (QPatch 16, Sophion Bioscience, Ballerup, Denmark) was performed as previously outlined [18], using the same internal and external solutions as in the conventional system. Inhibition by compounds was determined by the Hill equation fitting 9 concentrations. The results obtained with the QPatch 16 were confirmed by the conventional electrophysiological recordings. Compounds for testing were dissolved in the extracellular solution as stock solutions of $10 \mathrm{mM}$ and stored at $-20{ }^{\circ} \mathrm{C}$. These were diluted in the extracellular solution in amber tubes to desired concentrations before being applied directly to the recording chamber $(0.5 \mathrm{~mL})$ at a flow rate of $\sim 2 \mathrm{~mL} / \mathrm{min}$.

Electrophysiological results were re-plotted and fitted using Igor pro 6 (WaveMetrics, Lake Oswego, OR, USA). Data are reported as mean \pm S.E.M.; $n$ values refer to a number of individual cells tested. Statistical significance was evaluated by an unpaired two-tailed Student's $t$-test, using data obtained from at least three independent experiments. $P$ values $<0.01$ were considered significant.

4.2.4. Screening of endogenous voltage-activated $\mathrm{Na}^{+}$(Nav) and $\mathrm{Ca}^{2+}$ (Cav) channels

F-11 cells (DRG neuroblastoma mouse cell line, N18TG2, ECACC) were cultured using Dulbecco's modified Eagle's medium supplemented with $10 \%$ deactivated foetal bovine serum and $1 \%$ penicillin-streptomycin solution (Sigma-Aldrich) Wicklow, Ireland. Native Nav channels (tetrodotoxin-sensitive [24], were pharmacologically isolated by exposing the cells to $100 \mu \mathrm{M} \mathrm{Cd}{ }^{2+}$, whereas isolation of inward $\mathrm{Ca}^{2+}$ current was achieved by including $1 \mu \mathrm{M}$ TTX in the extracellular recording solution. Native $\mathrm{K}^{+}$currents were blocked by replacing $\mathrm{K}^{+}$ with equal molarity of $\mathrm{Cs}^{+}$in the internal recording solution $(125 \mathrm{mM}$ $\left.[\mathrm{Cs}]_{\mathrm{i}}\right)$. Inward $\mathrm{Na}^{+}$and $\mathrm{Ca}^{2+}$ currents were calculated from the average current peaks at $-30 \mathrm{mV}$ and $-40 \mathrm{mV}$, respectively.

\subsection{Computation}

A homology model for the rat Kv1.1 channel was developed and validated, as previously described [21,29]. For ligands, Accelrys Discovery Studio 3.5 (Release 3.5, Accelrys Inc., San Diego, USA), was utilised to enumerate tautomers, stereoisomers, and conformations. 


\subsubsection{Molecular docking.}

AutoDock 4 was used for molecular docking with flexible ligands $[30,31]$ Flexible residues in the protein were defined as residues 375-381 in each monomer [29]. A cubic grid of $140 \AA \times 140 \AA \times 140 \AA$ around the ion pore was constructed using the Autogrid program, with a grid point step of $0.375 \AA$. Default parameters were implemented in Autodock4 with 50 docking runs, while ga_num_evals was set to $25,000,000$ and ga_num_generations fixed at 27,000. The AutoDock Tools program [32] was employed for the generation of input files. The conformations showing lower free energy of binding for each ligand were further analyzed.

\section{Acknowledgments}

This work was funded by a Principle Investigator grant from Science Foundation Ireland (to J.O.D.), a DCU President scholarship (for S.K.), an Irish Research Council Scholarship (for D.D.) and the Programme for Research in Third Level Institutions (PRTLI) Cycle 4. The PRTLI is cofunded through the European Regional Development Fund (ERDF), part of the European Union Structural Funds Programme 2007-2013.

\section{Appendix A. Supplementary data}

Supplementary data to this article can be found online at https:// doi.org/10.1016/j.bioorg.2020.103918.

\section{References}

[1] M.C. D'Adamo, L. Catacuzzeno, G. Di Giovanni, F. Franciolini, M. Pessia, K(+) channelepsy: progress in the neurobiology of potassium channels and epilepsy, Front Cell Neurosci 7 (2013) 134.

[2] F.M. Ashcroft, Ion channels and disease: Channelopathies, Academic Press, San Diego, 2000.

[3] D.M. Kullmann, The neuronal channelopathies, Brain 125 (Pt 6) (2002) 1177-1195.

[4] D.N. Parcej, V.E. Scott, J.O. Dolly, Oligomeric properties of alpha-dendrotoxinsensitive potassium ion channels purified from bovine brain, Biochemistry 31 (45) (1992) 11084-11088.

[5] F.C. Wang, D.N. Parcej, J.O. Dolly, alpha subunit compositions of Kv1.1-containing $\mathrm{K}+$ channel subtypes fractionated from rat brain using dendrotoxins, Eur J Biochem 263 (1) (1999) 230-237.

[6] S.V. Ovsepian, M. LeBerre, V. Steuber, V.B. O'Leary, C. Leibold, J. Oliver Dolly, Distinctive role of KV1.1 subunit in the biology and functions of low threshold K(+) channels with implications for neurological disease, Pharmacol Ther 159 (2016) 93-101.

[7] J. Rettig, S.H. Heinemann, F. Wunder, C. Lorra, D.N. Parcej, J.O. Dolly, O. Pongs, Inactivation properties of voltage-gated $\mathrm{K}+$ channels altered by presence of betasubunit, Nature 369 (6478) (1994) 289-294.

[8] V.E. Scott, Z.M. Muniz, S. Sewing, R. Lichtinghagen, D.N. Parcej, O. Pongs, J.O. Dolly, Antibodies specific for distinct Kv subunits unveil a heterooligomeric basis for subtypes of alpha-dendrotoxin-sensitive $\mathrm{K}+$ channels in bovine brain, Biochemistry 33 (7) (1994) 1617-1623.

[9] V.E. Scott, J. Rettig, D.N. Parcej, J.N. Keen, J.B. Findlay, O. Pongs, J.O. Dolly, Primary structure of a beta subunit of alpha-dendrotoxin-sensitive $\mathrm{K}+$ channels from bovine brain, Proc Natl Acad Sci U S A 91 (5) (1994) 1637-1641.

[10] S.K. Coleman, J. Newcombe, J. Pryke, J.O. Dolly, Subunit composition of Kv1 channels in human CNS, J Neurochem 73 (2) (1999) 849-858.

[11] R.O. Koch, S.G. Wanner, A. Koschak, M. Hanner, C. Schwarzer, G.J. Kaczorowski, R.S. Slaughter, M.L. Garcia, H.G. Knaus, Complex subunit assembly of neuronal voltage-gated $\mathrm{K}+$ channels, Basis for high-affinity toxin interactions and pharmacology, J Biol Chem 272 (44) (1997) 27577-27581.
[12] A. Koschak, R.M. Bugianesi, J. Mitterdorfer, G.J. Kaczorowski, M.L. Garcia, H.G. Knaus, Subunit composition of brain voltage-gated potassium channels determined by hongotoxin-1, a novel peptide derived from Centruroides limbatus venom, J Biol Chem 273 (5) (1998) 2639-2644.

[13] O.G. Shamotienko, D.N. Parcej, J.O. Dolly, Subunit combinations defined for K+ channel Kv1 subtypes in synaptic membranes from bovine brain, Biochemistry 36 (27) (1997) 8195-8201.

[14] H.M. Brew, J.L. Hallows, B.L. Tempel, Hyperexcitability and reduced low threshold potassium currents in auditory neurons of mice lacking the channel subunit Kv1.1, J Physiol 548 (Pt 1) (2003) 1-20.

[15] H.M. Brew, J.X. Gittelman, R.S. Silverstein, T.D. Hanks, V.P. Demas, L.C. Robinson, C.A. Robbins, J. McKee-Johnson, S.Y. Chiu, A. Messing, B.L. Tempel, Seizures and reduced life span in mice lacking the potassium channel subunit Kv1.2, but hypoexcitability and enlarged Kv1 currents in auditory neurons, J Neurophysiol 98 (3) (2007) 1501-1525.

[16] B. Bagchi, A. Al-Sabi, S. Kaza, D. Scholz, V.B. O'Leary, J.O. Dolly, S.V. Ovsepian, Disruption of myelin leads to ectopic expression of $\mathrm{K}(\mathrm{V}) 1.1$ channels with abnormal conductivity of optic nerve axons in a cuprizone-induced model of demyelination, PLoS, One 9(2) (2014) e87736.

[17] S. Grissmer, A.N. Nguyen, J. Aiyar, D.C. Hanson, R.J. Mather, G.A. Gutman, M.J. Karmilowicz, D.D. Auperin, K.G. Chandy, Pharmacological characterization of five cloned voltage-gated $\mathrm{K}+$ channels, types Kv1.1, 1.2, 1.3, 1.5, and 3.1, stably expressed in mammalian cell lines, Mol Pharmacol 45(6) (1994) 1227-34.

[18] A. Al-Sabi, S.K. Kaza, J.O. Dolly, J. Wang, Pharmacological characteristics of Kv1.1and Kv1.2-containing channels are influenced by the stoichiometry and positioning of their alpha subunits, Biochem J 454 (1) (2013) 101-108.

[19] H. Wang, M.L. Allen, J.J. Grigg, J.L. Noebels, B.L. Tempel, Hypomyelination alters $\mathrm{K}+$ channel expression in mouse mutants shiverer and Trembler, Neuron 15 (6) (1995) 1337-1347.

[20] H. Wang, D.D. Kunkel, T.M. Martin, P.A. Schwartzkroin, B.L. Tempel, Heteromultimeric $\mathrm{K}+$ channels in terminal and juxtaparanodal regions of neurons, Nature 365 (6441) (1993) 75-79.

[21] A. Al-Sabi, D. Daly, P. Hoefer, G.K. Kinsella, C. Metais, M. Pickering, C. Herron, S.K. Kaza, K. Nolan, J.O. Dolly, A Rational Design of a Selective Inhibitor for Kv1.1 Channels Prevalent in Demyelinated Nerves That Improves Their Impaired Axonal Conduction, J Med Chem 60 (6) (2017) 2245-2256.

[22] R.A. Laskowski, M.B. Swindells, LigPlot + : multiple ligand-protein interaction diagrams for drug discovery, J Chem Inf Model 51 (10) (2011) 2778-2786.

[23] A. Al-Sabi, S. Kaza, M. Le Berre, L. O'Hara, M. Bodeker, J. Wang, J.O. Dolly, Position-dependent attenuation by Kv1.6 of N-type inactivation of Kv1.4-containing channels, Biochem J 438 (2) (2011) 389-396.

[24] K. Yin, G.J. Baillie, I. Vetter, Neuronal cell lines as model dorsal root ganglion neurons: A transcriptomic comparison, Mol Pain 12 (2016).

[25] H.B. Jensen, M. Ravnborg, U. Dalgas, E. Stenager, 4-Aminopyridine for symptomatic treatment of multiple sclerosis: a systematic review, Ther Adv Neurol Disord 7 (2) (2014) 97-113.

[26] S. Akhtar, O. Shamotienko, M. Papakosta, F. Ali, J.O. Dolly, Characteristics of brain Kv1 channels tailored to mimic native counterparts by tandem linkage of alpha subunits: implications for K+ channelopathies, J Biol Chem 277 (19) (2002) 16376-16382.

[27] M.V. Sokolov, O. Shamotienko, S.N. Dhochartaigh, J.T. Sack, J.O. Dolly, Concatemers of brain Kv1 channel alpha subunits that give similar K + currents yield pharmacologically distinguishable heteromers, Neuropharmacology 53 (2) (2007) 272-282.

[28] A. Al-Sabi, O. Shamotienko, S.N. Dhochartaigh, N. Muniyappa, M. Le Berre, H. Shaban, J. Wang, J.T. Sack, J.O. Dolly, Arrangement of Kv1 alpha subunits dictates sensitivity to tetraethylammonium, J Gen Physiol 136 (3) (2010) 273-282.

[29] D. Daly, A. Al-Sabi, G.K. Kinsella, K. Nolan, J.O. Dolly, Porphyrin derivatives as potent and selective blockers of neuronal Kv1 channels, Chem Commun (Camb) 51 (6) (2015) 1066-1069.

[30] R. Huey, G.M. Morris, A.J. Olson, D.S. Goodsell, A semiempirical free energy force field with charge-based desolvation, J Comput Chem 28 (6) (2007) 1145-1152.

[31] G.M. Morris, D.S. Goodsell, R. Huey, A.J. Olson, Distributed automated docking of flexible ligands to proteins: parallel applications of AutoDock 2.4, J Comput Aided Mol Des 10 (4) (1996) 293-304.

[32] G.M. Morris, R. Huey, W. Lindstrom, M.F. Sanner, R.K. Belew, D.S. Goodsell, A.J. Olson, AutoDock4 and AutoDockTools4: Automated docking with selective receptor flexibility, J Comput Chem 30 (16) (2009) 2785-2791. 